\title{
Scratching the Surface of Spectacle: Black Hypermasculinity and the Television Talent Show
}

Laura Robinson, University of East London

\begin{abstract}
This study explores the construction of black hypermasculinity in television talent show competitions through the re-valuing of spectacle as an aesthetic experience. Drawing on a screendance analysis of eighteen duet, trio and group performances featured in ITV's Britain's Got Talent (BGT) and Sky1's Got To Dance (GTD) between 2008-2013, this study explores the circulation of black hypermasculinity and the potentiality for an alternate reading of spectacular displays of athleticism. Building upon Kristen Whissel's concept of the emblematic nature of the special effect in cinema, the re-valuing of televised spectacles reveals themes regarding the black male experience in these competitions. Rather than dismissing these performances as commercial spectacles that recirculate notions of black hypermasculinity, these corporeal and televisual special effects instead highlight the thematic narrative of the reality television journey through themes of aspiration and transformation. Crews constructs images of superheroes, cartoons, animals and cyborgs, manipulated by camera angles and editing, that operate as both light entertainment and a reflection of the young black male experience in mediascope of reality television. The creation of spectacular and glossy images on screen therefore reveals the potentiality of a fluid gender and racialized representation.
\end{abstract}

Keywords: screendance, hip-hop, street dance, spectacle, reality television

Despite Yvonne Rainer's disapproval, spectacle, by its very nature, has always commanded attention. ${ }^{1}$ In the context of screendance, the formulaic yet entertaining premise of dance on television talent show competitions has provided a regular digital platform for corporeal spectacles, none more so than the highly combustible, attentiondeficit performances of U.K. Street dance crews. Bombarding the viewer with fast-flying images of physical dexterity, crews amalgamate gymnastic vocabulary, martial arts infused tricking and the flair of breakdance power moves with black social dance styles, all contained within a two-and-a-half-minute framework. Coupled with shifting camera angles, sharp editing between frames, and on-stage pyrotechnics, audiences on screen and at home are able to achieve the "Wow-affect."

Tied into this spectacular viewing experience, however, is the re-circulation of blackness in a mediated format. The circulation of televised images of young males performing

The International Journal of Screendance 9 (2018).

(c) 2018 Robinson. This article is published under a Creative Commons Attribution 4.0 International License (https:/creativecommons.org/licenses/by/4.0/) 
seemingly impossible athletic stunts, high impact climatic finishes, performed with a hard-hitting dynamic and framed within a medley of black social dance styles, continues to reaffirm the stereotypical image of the black hypermasculine male. As Thomas DeFrantz observes in his study of hip-hop habitus, "black social dances distributed by the mediaplace veer towards familiar spectacles of excessive activity and hyperkinetic impossibilities." ${ }^{3}$ Are these performances anything more than mediated representations of black masculine excess to be consumed by the white gaze?

Yet, the creation of spectacular images by all-male crew performances is a powerful tool for engaging the voting home viewer. The impressive technical precision of highly disciplined bodies, the male dancers' virtuosic aerial stunts that fly across the stage, and the rapidly changing shapes, forms and transitions in the choreography presents an engaging visual display. The layered effects of lighting, camera angles, pyrotechnics and the editing stage in the production process further enhance these performances with continued emphasis on surface, style and presentation. Because of such an emphasis on the glossy image, little critical analysis is given to the aesthetics of the spectacular, and, consequently, the mediatization of popular dance on television due to the dismissal of these performances as mere spectacle.

In the analysis of Hollywood cinema, Erlend Lavik observes that "the use of spectacle...tends to be conceived of as an appeal to the lowest common denominator" and that higher value is placed on the narrative of the film rather than its excessive visual displays. ${ }^{4}$ Rosalind Galt mirrors this diminishing of spectacle's value, stating that "the rhetoric of cinema has consistently denigrated surface decoration, finding the attractive skin of the screen to be false, shallow, feminine, or apolitical. ${ }^{5}$ Despite this devaluing of spectacle's aesthetic properties and its lack of attention in academic scholarship, spectacle is still favored in mass popular culture, evidenced by capitalist gains: high television viewing figures, sold out concerts, and record breaking box-office hits.

As a consequence of late capitalism, spectacle also refers to an ideological condition of a commodified society whereby social relations are replaced by images. ${ }^{6}$ Crews perform in the overall spectacle of a media saturated contemporary society where real experiences are replaced with dazzling images of artifice. The positionality of male dancing bodies of color becomes a complex balance between the necessity to remain visible within the media spectacle of the competition and the loss of their lived experience due to the manipulation of reality and its reduction to spectacle. The value of focusing solely upon these spectacular images of black hypermasculinity is then twofold: the re-valuation of the role of spectacle as an aesthetic experience in television, and the potential for disparate readings of the highly constructed personas of young black men on reality television.

This study thus sets out to explore three key questions: how does black hypermasculinity operate and circulate in the mediascape of television; how do 
constructions of hypermasculine blackness performed in a crew intersect with spectacle, and what more can be garnered from performances of a spectacularized black hypermasculinity in a screendance setting? Drawing upon film theory, I argue that while television talent shows reduce crew choreographies to commercially viable images of hyper-blackness, it is the black male experience in these competitions, particularly through such emblematic themes of aspiration and transformation, that enable a re-valuing of televised spectacle. These ideas will be explored through a screendance analysis of eighteen examples, including duet, trio and group performances featured at the audition, semi-final, and final rounds of ITV's Britain's Got Talent (BGT) and Sky1's Got To Dance (GTD) between 2008-2013.'

\section{Black hypermasculinity on television}

As explored in DeFrantz's and Gonzalez's timely anthology into black performance theory, "black sensibilities emerge whether there are black bodies present or not." ${ }^{8}$ Blackness circulates in a multiplicity of practices and is deeply rooted in history, diaspora and corporeal exchange. ${ }^{9}$ This circulation and reaffirmation of an enduring blackness, and, consequently, stereotypical visual representations of otherness, is particularly apparent in televised depictions of young black males. Cultural scholar bell hooks notes that black men have had little say on their representation, and historical depictions include "animals, brutes, natural born rapists, and murderers." ${ }^{10}$ These negative stereotypes continue to determine the representation of the black male figure, and, in order to gain visibility in institutional power structures of white discourse, these figures must either conform or attempt to work against such undesirable representations. ${ }^{11}$

In the late twentieth century, television corporations produced the same omnipresent black body in discourses surrounding black heterosexual masculinity. In a U.K. context, black popular cultural expressions historically shaped and influenced depictions of Black Britishness on television. ${ }^{12}$ These televised representations aimed to demonstrate a corporations' cultural diversity, and, to some extent, the attractive commodity of difference. Such two-dimensional representations included the heroic status of black rappers, the naturalized ability of athletes, the threatening image of black gang members, and the representations of noble African warriors. In her analysis of the televised objectification of the black British athlete Linford Christie, Sarita Malik argues that "the black body functions as the agent of fascination and desire," suggesting that the allure and envy surrounding black male physicality reinforces the passive objectification of the black male form. ${ }^{13}$

Hip-hop dance practices, and their rebranding in the media sphere as "Street," "Commercial," and "Urban" dance forms, continue to construct tropes of blackness through global circulation, resulting in the commodification of their associated identities, attitudes and aesthetics. B-boys historically constructed the masculinized self 
through their virtuosic and athletic performances in the cypher, demonstrating strength, power and aggression through improvised floor work and power moves in a competitive environment. ${ }^{14}$ When re-presented from their vernacular context in the commercial market, the hip-hop dancing body becomes a recognisable and easy to read marker of essentialised blackness, signifying coolness, attitude, music, dress and swagger. ${ }^{15}$ Such over-representation of certain screened images of blackness in the media, termed "hypervisibility, ${ }^{16}$ or, as Grey defines, "hyperblackness, ${ }^{17}$ speaks to the visual currency of these images and their embodiment and appropriation by new audiences. Dancing bodies who perform such "hypervisibility" hold cross cultural appeal and high currency in the commercial market, as consumers can buy into the imagined reality of black authenticity and the exotic other. ${ }^{18}$ These performances screened on music videos, films, advertising, social media, and television appeal to "everyman" and "every-woman" in the construction of self-identity through access to an imagined black attitude and physical expression. ${ }^{19}$ Satirically, the term hypervisibility likewise alludes to the invisibility of the black subject in other areas of society, reinforcing ideas of blackness as unfinished and incomplete.

So what might black hypermasculinity look like in the context of the television talent show? In the example of Cerebro: a crew formed of six young black males who competed on GTD in 2011, ${ }^{20}$ the emphasis is placed on naturalized athleticism and muscular display, with a nod towards phallic hardness. The crew begin their audition with one dancer held upside down and slowly hinging at the waist, with the other dancers fanning out around the stunt. This sustained pose quickly spreads out across the stage, shifting to a unison sequence of mimetic arm gestures and breaking freezes. Dancers create a piston effect in canon by each rapidly stiffening their prone bodies to physically jolt off the floor in a diagonal line to the even drumbeat of the music. Following this impressive display of core strength, the dancers roll over and perform a controlled push off from the floor to standing in unison, gradually lifting their shirts to display their tightly sculpted torsos while smiling and nodding to the audience and then dropping their shirts back into place. As a finale, one dancer performs a series of linear gymnastic hand springs and round-offs over the rest of the crew and seamlessly inserts himself amongst the crew's pyramid formation. 


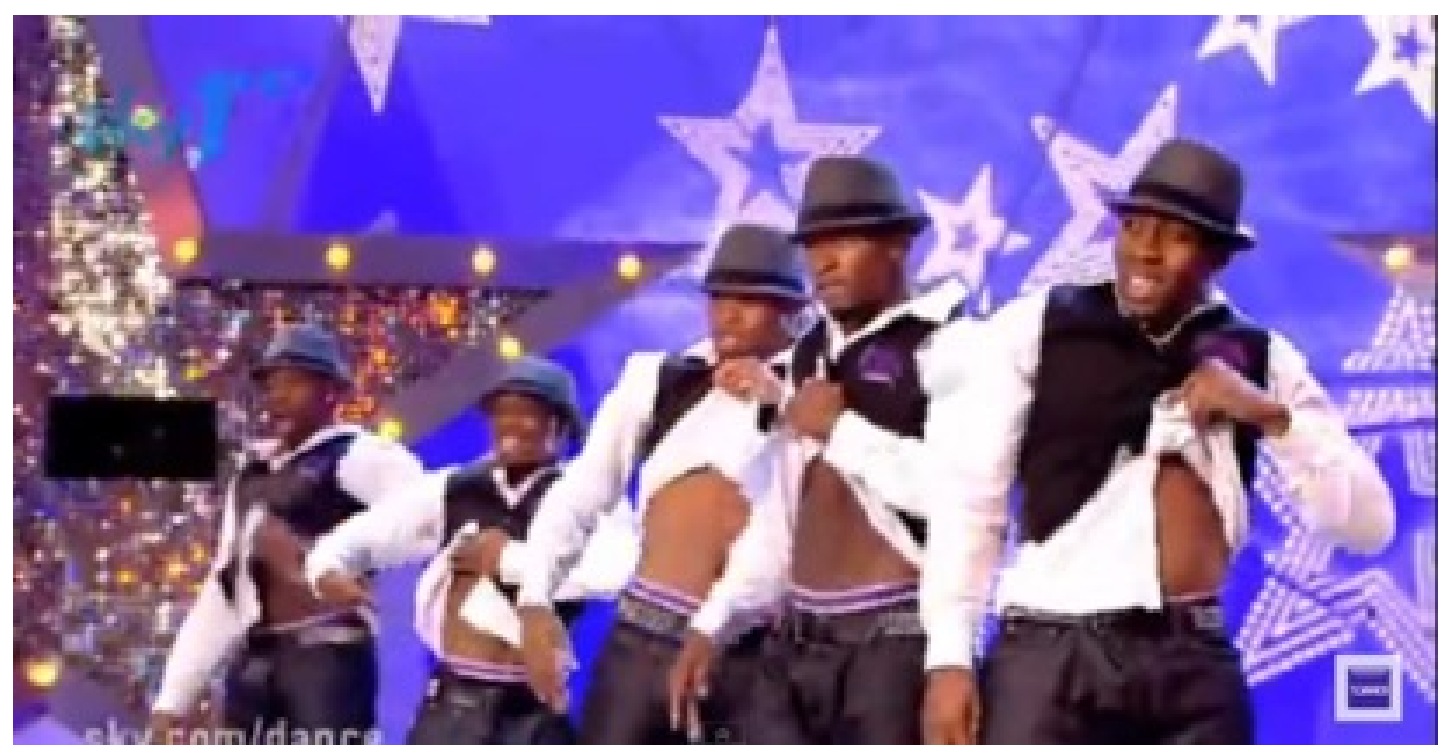

Figure 1 Cerebro

This hyperbolic choreographic display is mimicked and amplified in the filming and editing of the crew choreography, as well as in the wider television production. Shifts between choreographic phrases involve split-second transitions between a moving floor camera, an overhead crane shot of the dancers, and a shot of judge Adam Garcia nodding his head at the performance. The impetus of the dance is propelled by the camera movement rather than the stage action itself, with the change in angles and the sweeping action of the floor camera adding further momentum to the unwieldy and fluctuating transition between social dance styles, gymnastic stunts, and narratives. Prerecorded VT segments of the crew are interspersed with stunts and high color graphics, keeping bodies in action and in flight even during stationary interviews. During the judges' comments following crew performances, judges use metaphors of force, detailing how crews came out with "attack," "hit it hard," or "smashed it out the water."21

Pre-recorded VT segments additionally situate street dance crews, such as Cerebro, in false urban environments in order to maintain the illusive stereotypical markers or race and class, with a particular emphasis on the reproduction of blackness. Flawless crew are filmed walking around the streets of London without an explanation of their location, The A Team are depicted rehearsing their choreography outside a block of flats in a concrete open area, while Ruff Diamond are filmed performing gymnastic stunts in a disused factory car park. ${ }^{22}$ Removed from their dance studio environments and placed within a constructed urban aesthetic, the television production continues to associate the black dancing body with "the streets": the mediated representation of the origins of hip-hop cultural styles. ${ }^{23}$

Following these examples, do these highly produced and screened crew performances reveal anything more than a regurgitation of fixed notions of black hypermasculine 
excess? Drawing upon ideas derived from film theory, I argue that the possibility for an alternative reading lies in the notion of spectacle as an aesthetic experience.

\section{Spectacular digital cultures}

Since the late 1940s, the privatization of the spectacular experience through home television screens both increased the spectator's control of the medium, whilst at the same time reduced the sensual impact of the overall visual digital spectacle. Unlike the blackened theatrical environment of the cinema and the enhanced size of the cinema screen, the location of television in the home environment equated to a distracted gaze due to the temporal and spatial division between the spectacle and the spectator. These distractions are further amplified with the mobility of the twenty-first century television experience. Smaller screens, including smartphones and tablets, allow fingertip interactivity between television show and social media platforms, providing a further fragmented digital viewing experience. Consequently, small screen spectacles do battle to attract the attention of the distracted gaze.

In his study of visual digital cultures, Andrew Darley states that the proliferation of digital imaging technologies has fuelled the recent contemporary resurgence of spectacle in cinema and television. ${ }^{24}$ These include the use of wire removal software, green screens, digital rendering, image based rendering, CGl, digital 3D motion capture, and the layering of live action and computer-generated images. Such advanced camera mobility sweeps and zooms the spectator through the filmed action, and rather than merely capturing images in front of the camera lens, these stylistic features become part of the visual experience. Such technologies reveal key similarities with the early emergence of popular entertainment in the nineteenth century due to their heightened use of "form, style, surface, artifice, spectacle and sensation," and a shared emphasis on arresting the senses through a fusion of technique and skill with mediated technologies of representation. ${ }^{25}$

In her study of the decorative image, Rosalind Galt challenges historical logocentric understandings of spectacle and narrative, and argues that the increased emphasis on the surface image of the screen through performances of excess is also emblematic of the narrative and politics of the context of the screened subject. ${ }^{26}$ In a film context, Galt describes these heightened aesthetics as including "deep colors [sic], arabesque camera movement, detailed mise-en-scène [the design aspects of the film], and an emphasis on cinematographic surface." ${ }^{27}$ Similarly, Kristen Whissel's study into spectacular digital effects in contemporary cinema explores how special effects articulate and expand the possibilities of viewing. ${ }^{28}$ In particular, Whissel identifies two key styles of visual effect that are accomplished through cinematic digital technologies relevant to this study: "the illusion of radical, gravity-defying vertical movement" and "the corporeal and spatial 'plasmatics' made possible by the morph effect." ${ }^{29}$ Instead of viewers losing 
themselves in the empty spectacle of special effects, these digital technologies reveal "complex concepts and themes essential to the film's narrative." ${ }^{\text {"30 }}$

Despite diminished budgets and smaller screens, the application of these ideas to a televised context allows an analysis to move beyond an exploration of vacuous images and regurgitated stereotypes. By placing renewed importance on the aesthetic experience of these screendance performances, (constructed by both choreography and the wider television production), one can instead consider the wider outcomes that arise from both corporeal and digital spectacle within these performances. In the context of the televised street dance crew, I argue that two key themes emerge that bear significance in the televised representation of black masculinity: aspiration and transformation.

\section{Aspiring to the Vertical}

In Ruff Diamonds semi-final performance on series four of GTD, one dancer stands on the linked hands of two other dancers, vaults backwards performing a double back somersault, and lands on his back. ${ }^{31} \mathrm{~A}$ wide shot taken from stage left captures the sheer height of the feat, with the camera cutting to judge Aston Merryweather who jumps up and screams at the level of danger of the stunt. Following this stunt, viewers witness consecutive gymnastic displays: a back flip and a round-off from a solo dancer, a front flip over another dancer, a back flip performed in unison by three dancers, a back flip propelled from the linked hands of another dancer, and finally a solo back flip on the last explosion of the music.

Crews, such as Ruff Diamond, regularly extend along the vertical plane of the screen through athletic stunts influenced from breaking, gymnastics, cheerleading, martial arts, and tricking. These bodies appear to defy gravitational limitations, executing virtuosic aerial stunts usually only achieved through the intervention of technology upon the body. Dancers perform solo stunts both away from the body of the group and also as a collective in unison, with the risk increased by performing multiple stunts over the top of other dancers and being elevated by crew members to allow more height and multiple rotations in the air. In a duet example, Urban Jokers' semi-final performance incorporates one dancer leap frogging over another, with the base dancer suddenly standing up at the moment of the jump, launching the second dancer further into the air. ${ }^{32}$ In a group example, Antics incite a surprised reaction from the judging panel in their 2012 audition when one dancer is catapulted into the air by the linked arms of two other dancers. ${ }^{33}$ He partially disappears off the wide camera shot due to the height of the stunt, increasing the implausibility of the stunt. The camera immediately cuts back to judge Ashley Banjo, who leans forward, slams his hands on the desk, and yells out at the implausibility of the stunt. 


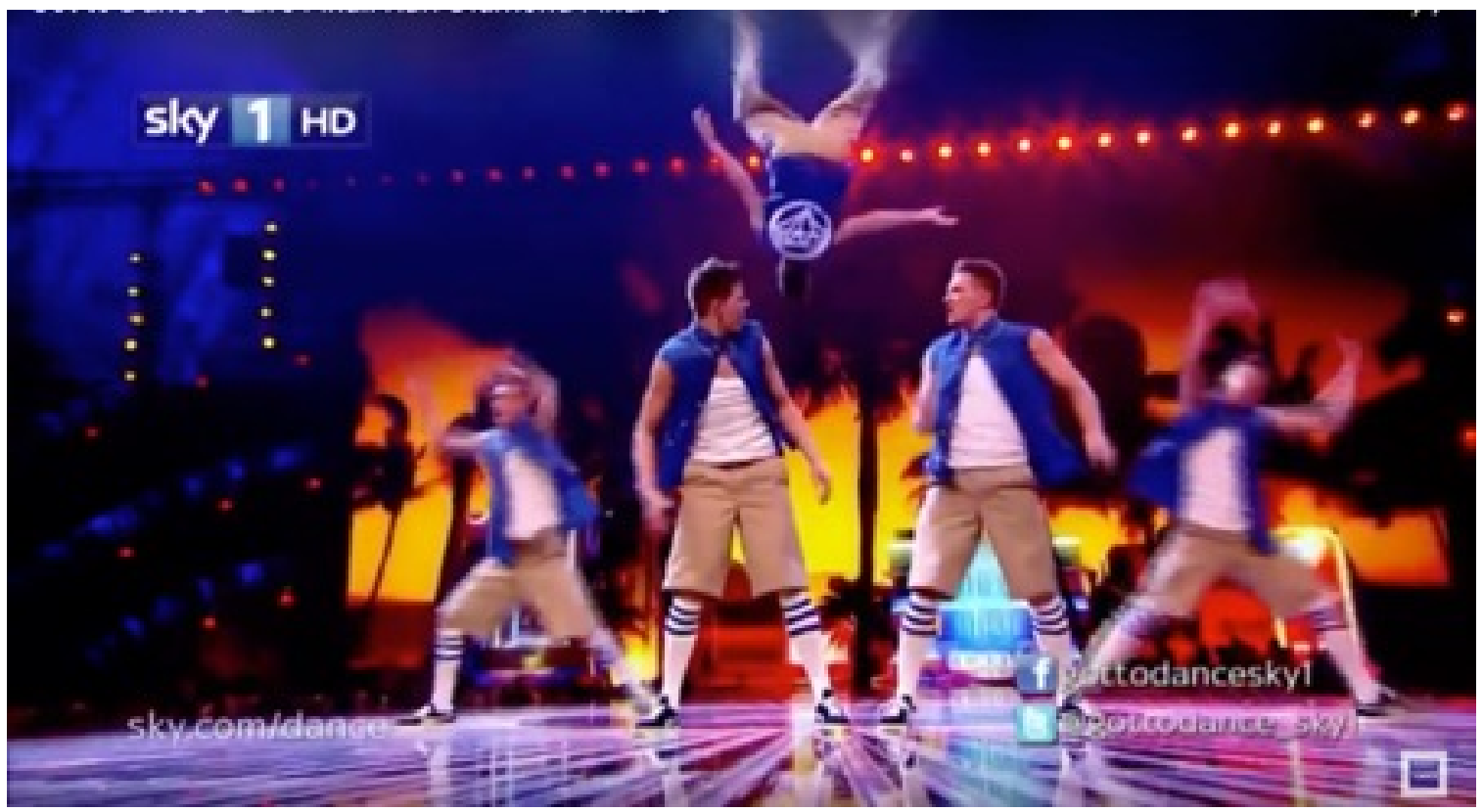

Figure 2 Ruff Diamond

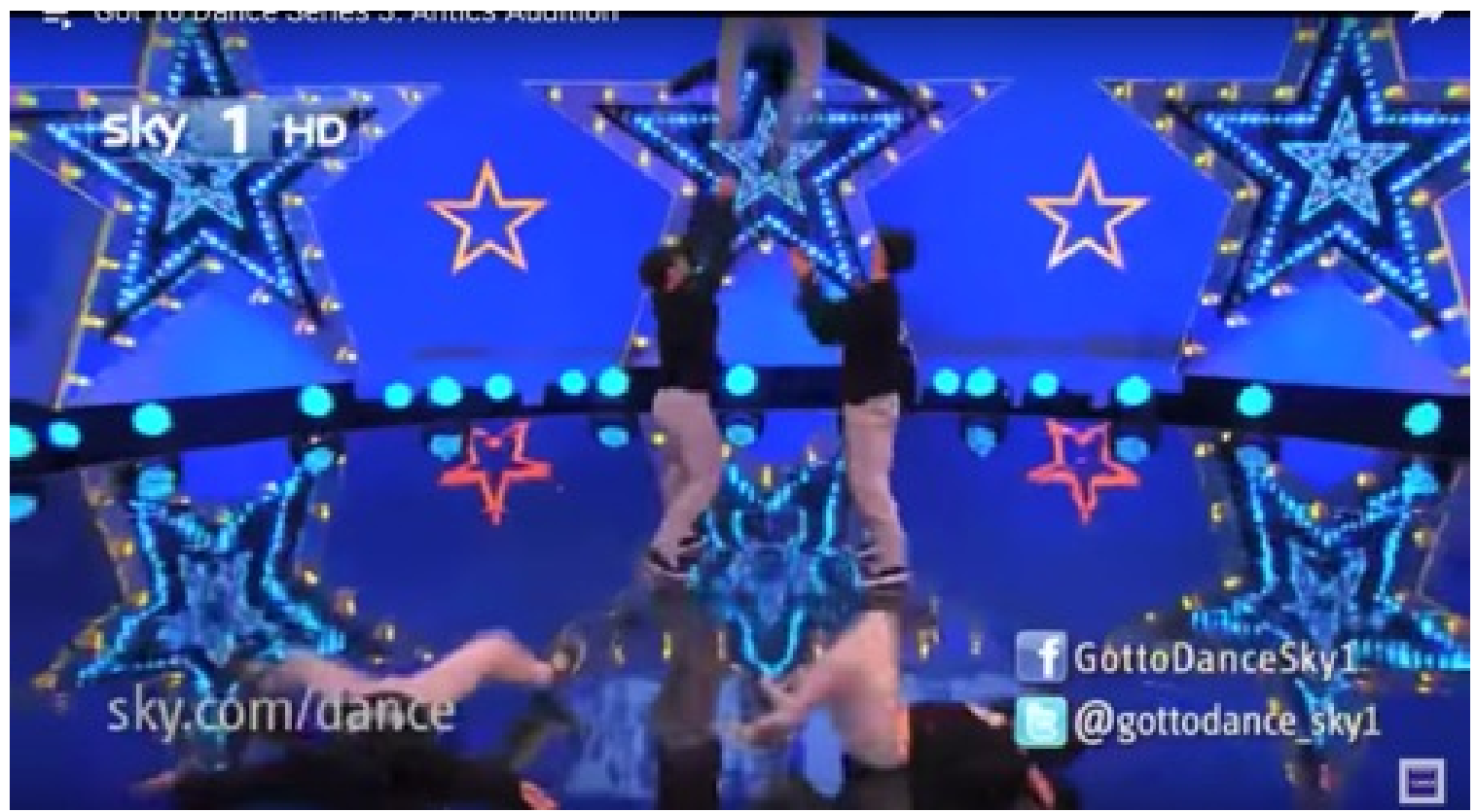

Figure 3 Antics

Within a film context, Whissel observes that blockbuster films create "breathtaking imaginary worlds defined by extreme heights and plunging depths." ${ }^{34}$ Since the 1970s, the exploitation of the vertical axis of the screen not only includes human feats of jumping and falling, but utilizes "models, miniatures, blue screens, mattes and motion control" to manipulate characters and scenery along the screen's vertical trajectory. ${ }^{35}$ With advancements in wire removal technology, digital animation and stunt doubles, 
spectators witness film bodies that can manipulate their surroundings in the elongated stretch of the cinematic screen. In the television talent show context, production budgets do not allow for the same quality of visual experience, and post-production edits cut between camera angles rather than adding additional digital spectacle effects. The positioning of the camera lens, however, continues to heighten this emphasis on verticality. Both $B G T$ and GTD shoot from the lower edge of the stage space shooting upwards, increasing the longevity of the perspective to give the appearance of a higher stunt. These explosive and cinematic moments include the trio $A 3$ 's unison performance of a front flip falling into split legs, shot from the foot of the stage and giving the appearance of the dancers falling towards the camera. ${ }^{36}$

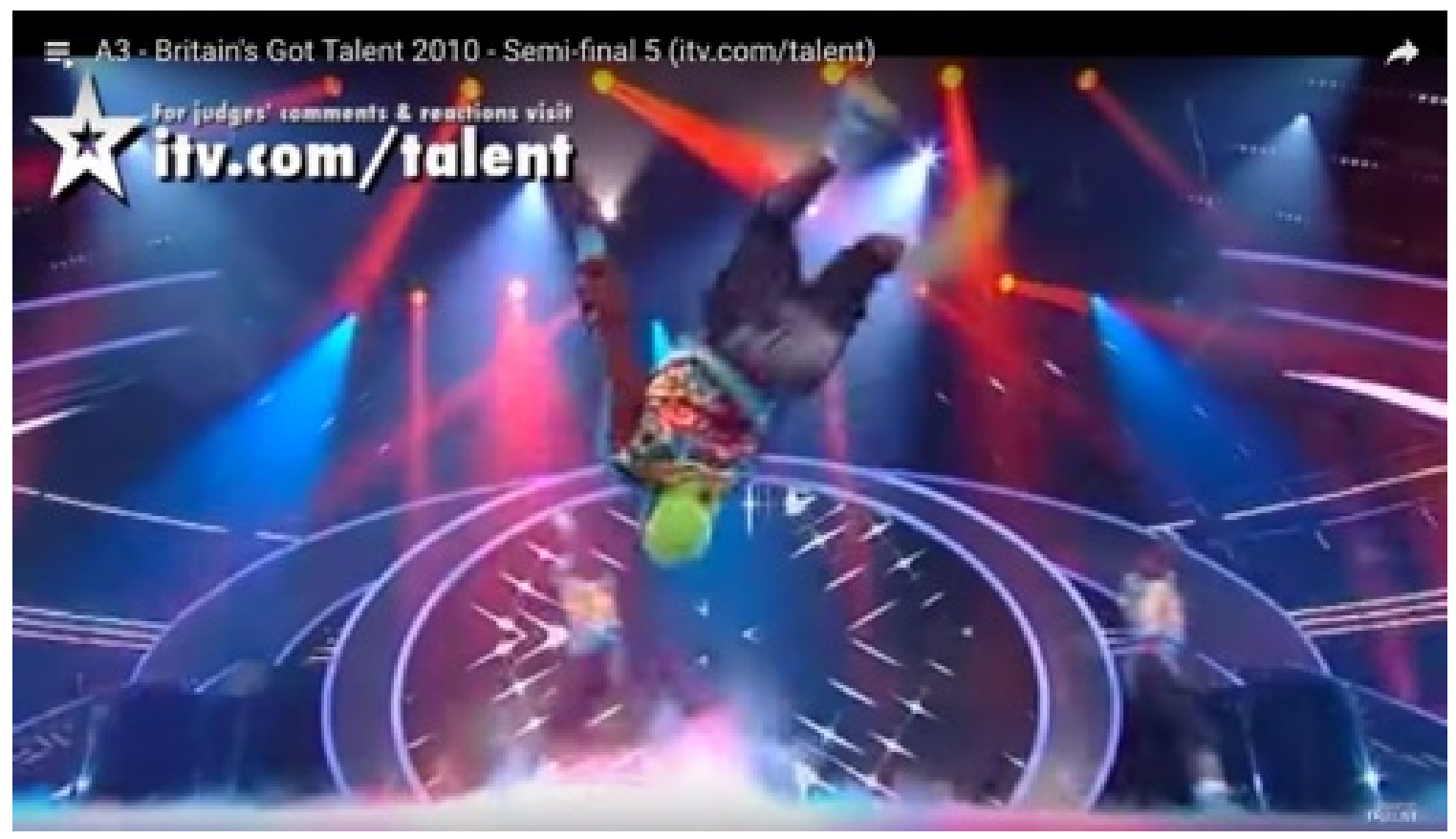

Figure $4 A 3$

Similarly, in Ruff Diamonds semi-final performance, a low camera positioned at the foot of the stage creates the impression of a dancer's aerial routine almost flying into the camera lens. ${ }^{37}$ This extreme close-up immediately cuts to a long shot of the circular stage capturing the crew judging panel and studio audience, thus contrasting the depth of the perspective with the previous vertical stunt of the solo dancer. 


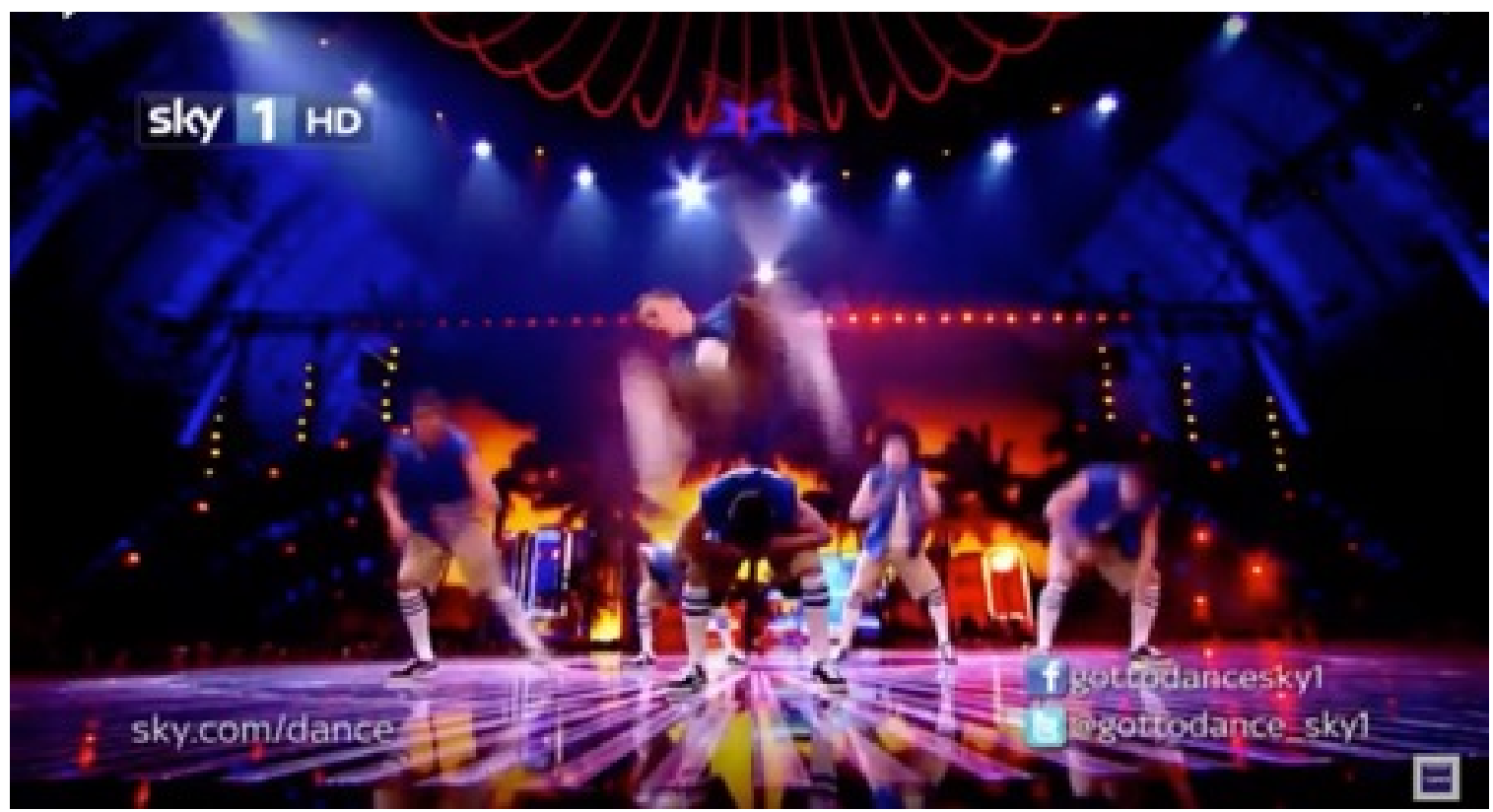

Figure 5 Close up of RuffDiamond

The rise and fall of bodies is also highlighted in the crews' defiance of gravity. In Flawless's audition on BGT, an overhead camera captures the crew in a stationary apex triangle formation and a single lying down dancer upstage center. ${ }^{38} \mathrm{He}$ pushes his body weight upwards to balance on his head, remaining there for an unnaturally long pause until inevitably falls forward flat on the floor, maintaining his taut torso and leg position.

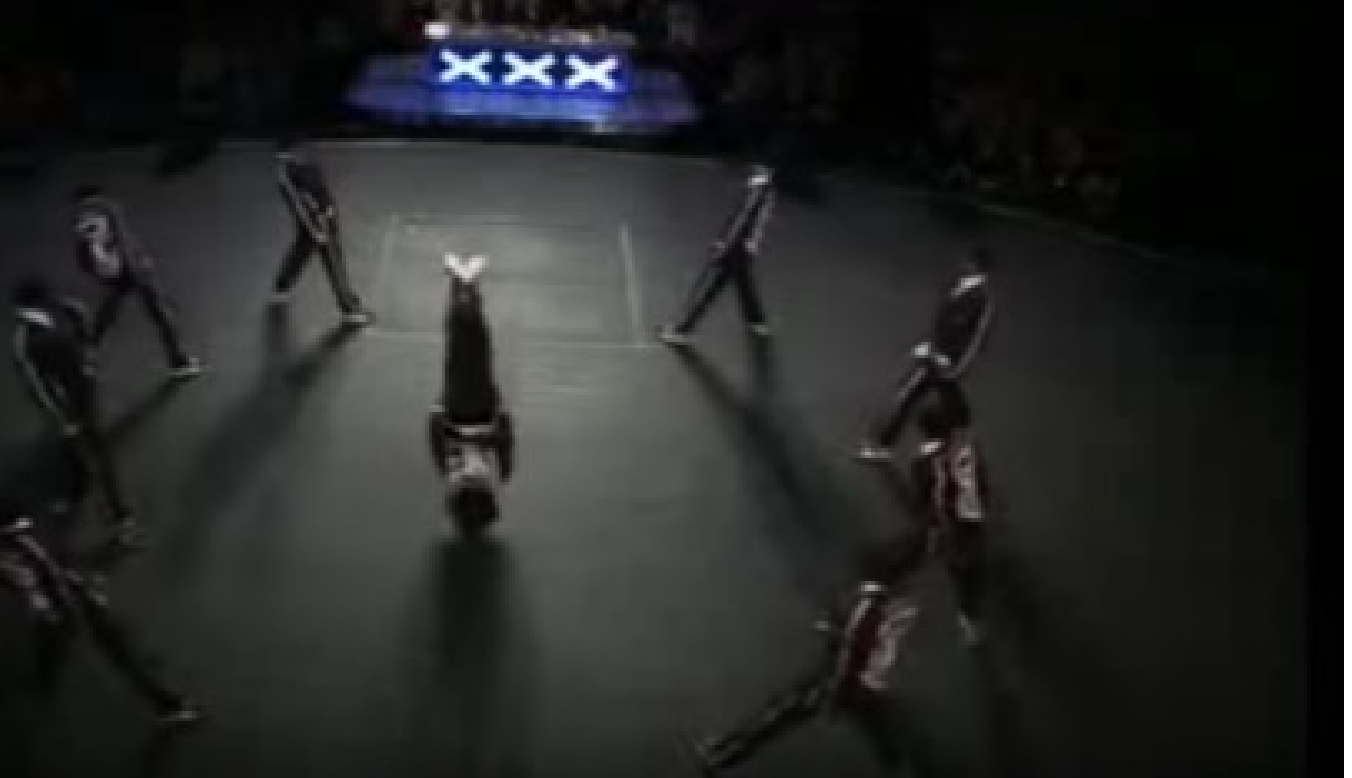

Figure 6 Flawless 
In RuffDiamonds final performance in series four, five dancers stand in a horizontal line and lean back towards stage left in unison. ${ }^{39} \mathrm{~A}$ single dancer mirrors this off-balance lean but in a precarious handstand, pushing the limitations of his own off-balance. While the small screen may not utilize wires, miniatures or blue screens, it is the dancing bodies themselves that create the special effect.

In a cinematic context, such emphasis on the vertical creates breath-taking special effects that, according to Whissel, signify struggles of power and issues of ascent and descent. ${ }^{40}$ The vertical thus becomes emblematic of the protagonist's upward mobility or their untimely descent in relation to the "historical, familial, and traditional past." ${ }^{141}$ In the context of the crews' competitive performance, crews act in excess of their staged performances by choreographically mimicking the elongated vertical screen through their physical feats, while at the same time inevitably falling back to the ground. I maintain that this continued emphasis on launching upwards into the vertical is indicative of the contestants' physical strive and aspiration in a competition concerned with upward mobility through personal struggle. By filling the vertical length of the screen, and, in some cases, disappearing off the screen, crews mirror the highs and lows of the reality television narrative, whilst ensuring maximum visibility within the context of the techno-spectacle of prime-time reality television.

Importantly, this emphasis on aspiration, as depicted through the aesthetic emphasis on the vertical, also has the potential to develop limiting images of black hypermasculinity. In particular, the continued emphasis on the vertical plane through choreography and screen techniques draws parallels with popular screen images of the male superhero. The athletic feats, the defiance of gravity, and the emphasis on flight, all create images of superhuman beings. In comic books, cartoons, and Hollywood blockbuster cinema, popular culture situates superhero characters, such as Superman or Batman, as the epitome of hypermasculine and hegemonic masculine superiority. Superheroes sit within a moral framework whereby they embody Western liberal ideals of law enforcement and the protection of human citizens. Enabled through superhuman armory, strength, skill and weaponry, the fantasy figure of the superhero amplifies the seemingly naturalized attributes of hypermasculinity.

Such a paradigm between street dancers as superheroes is already established in the U.S. web based television series, The League of Extraordinary Dancers. ${ }^{42}$ The narrative situates the majority male cast of Street dance performers as having superhuman abilities, with each hip-hop dance technique representing a special power. Dancers transcend the limitations of corporeal skill by presenting athletic prowess usually only achieved through digital editing and in the cinematic depictions of superhero action sequences. In the case of the televised crew performances, it is the bodies of the dancers themselves create this lengthening of the dimensions of the performance space, amplified by the production techniques. 
By framing these crews as superheroes who transcend the vertical, these performances hold the representational power and possibility for "fantastic (re) imaginings of black identity." ${ }^{\prime 3}$ In his study into black American superheroes, Adilifu Nama describes characters such as the Falcon; a black superhero who appeared in Captain America in 1969, as a representation of "our dreams, desires, and idealized projections of our selves." ${ }^{\prime 4}$ Black superhero comic characters, such as those featured in the recent Marvel installment of Black Panther, make a significant departure from limiting stereotypes, and through their circulation problematize negative discourses and assumptions surrounding black identity. ${ }^{45}$ By aspiring to aesthetically achieve the superhuman through the vertical plane, these crews aspire to be read as more than a reductive signifier of black hypermasculinity.

\section{Transformation}

Antics open their audition on series three of GTD in a tight huddle on center stage. ${ }^{46}$ Suddenly, ten arms shoot out from the black mass of hoodies and hats, retracting in and out like animal spines and waving side to side like tentacles. In the opening of their final performance in the same year, dancers stand in a vertical line with overlapping arms and open their hands and arms inwards and outwards in a jaw like fashion, complemented by the front dancer's menacing facial expression. ${ }^{47}$ The crew play with animalesque images throughout their choreographies, creating the image of a snail sliding along the floor in their semi-final performance in GTD series three ${ }_{1}^{48}$ and opening their series four final with the crew crawling along the stage floor like oversized insects, captured by the overhead crane shot of the camera. ${ }^{49}$

Transformation plays a key role in competitive street dance crew choreography. While crews create a collage effect through their fusion of NuSkool hip-hop choreography with funk styles, breaking, hip-hop party dances, Krump, house dance, and waacking, these sequences are interspersed with their metamorphosis into animals, machinery, cyborgian robots, and cartoon characters. These anamorphic, mechanized, and digitized images are abandoned as quickly as they are created, as crews rapidly shift to the next stage of their two and half minute choreographies. For example, Back2Backs audition briefly creates the comedic image of one dancer riding a bicycle, using the other four dancers to create the mechanics of the bike itself..$^{50}$ 


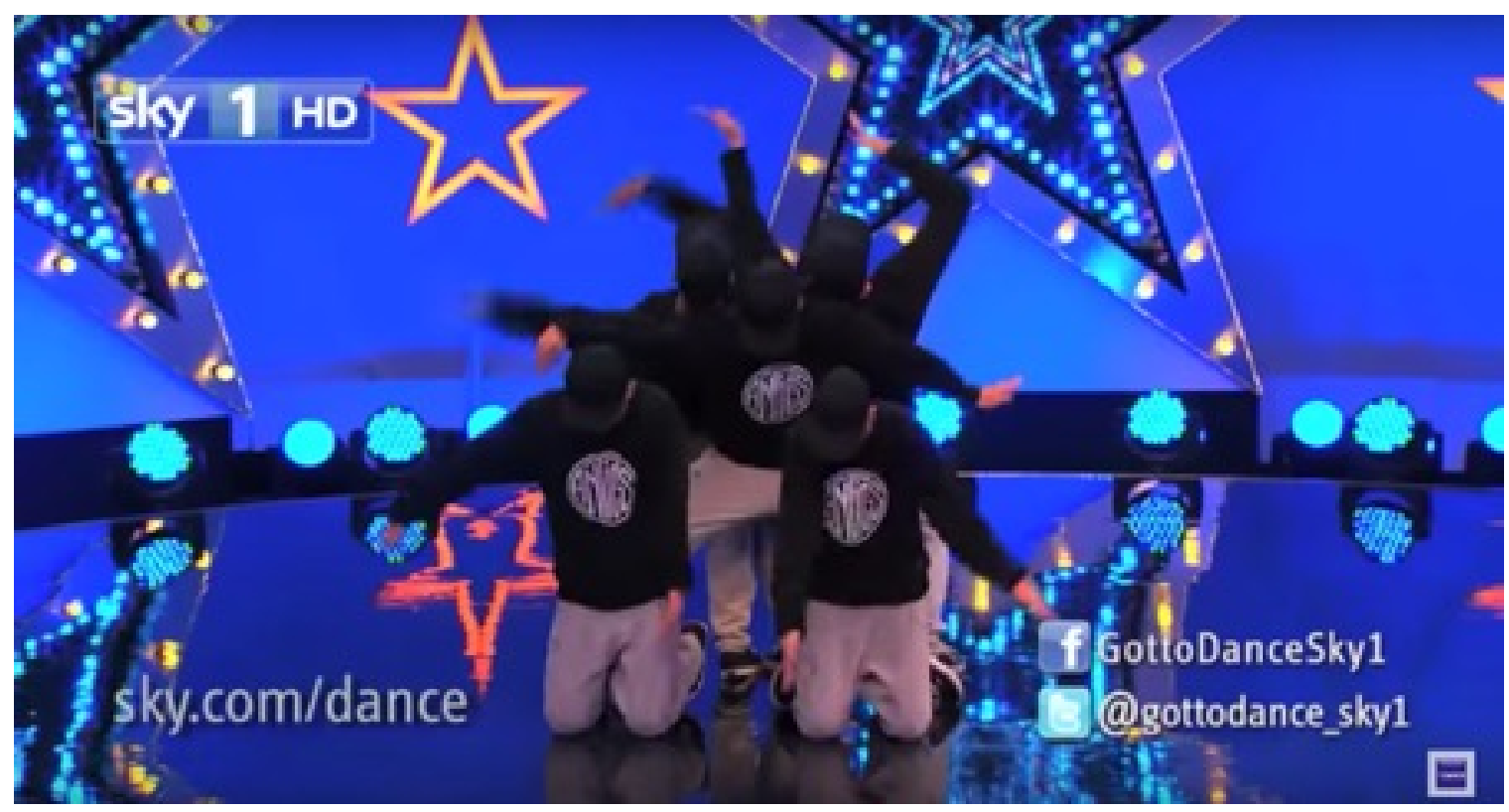

Figure 7 Antics Audition

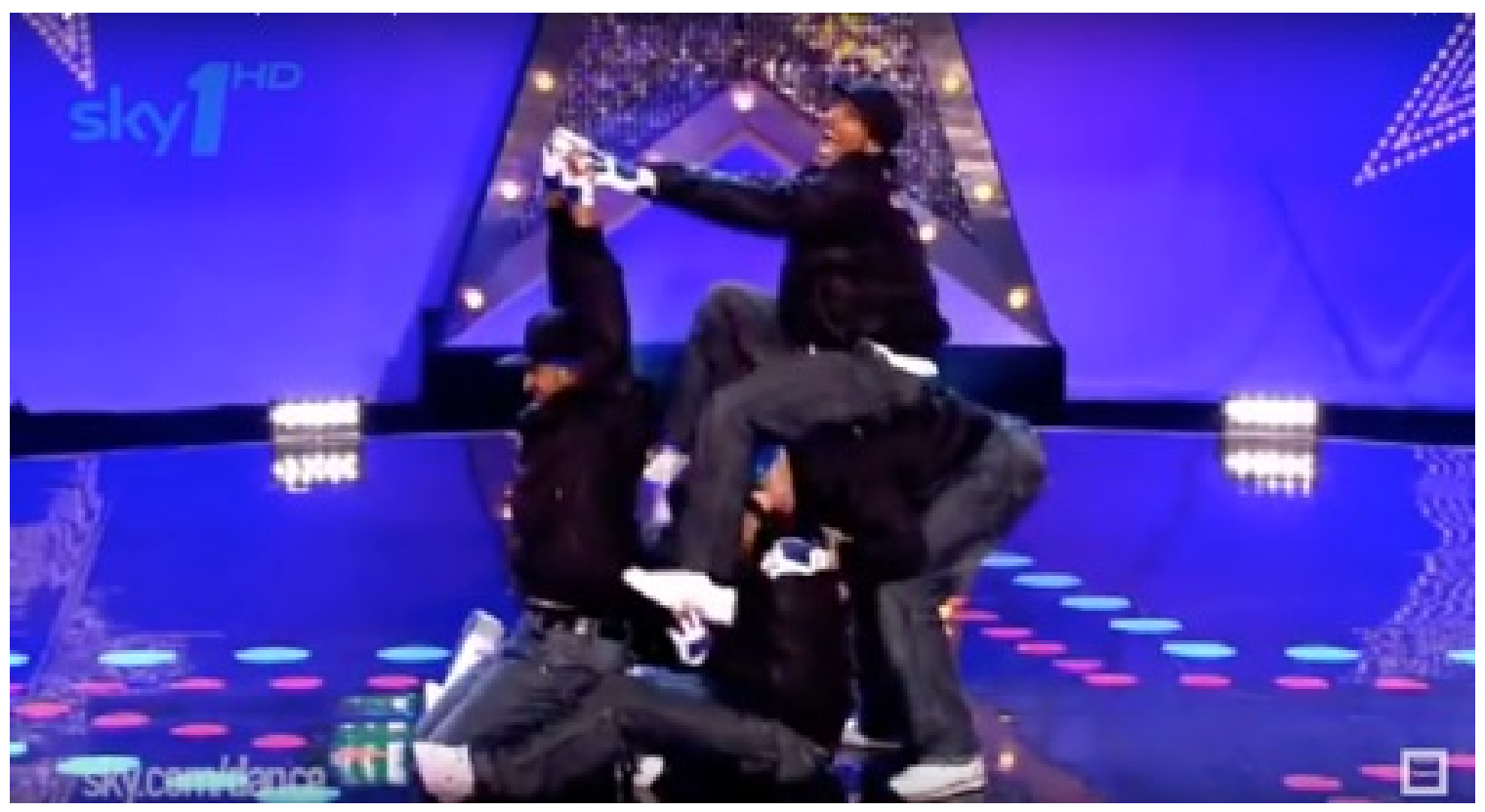

Figure 8 Back2Back

Abyss's audition features the formation of a helicopter, with one dancer elevated above the crew and spinning in the air like a propeller. ${ }^{51}$ 


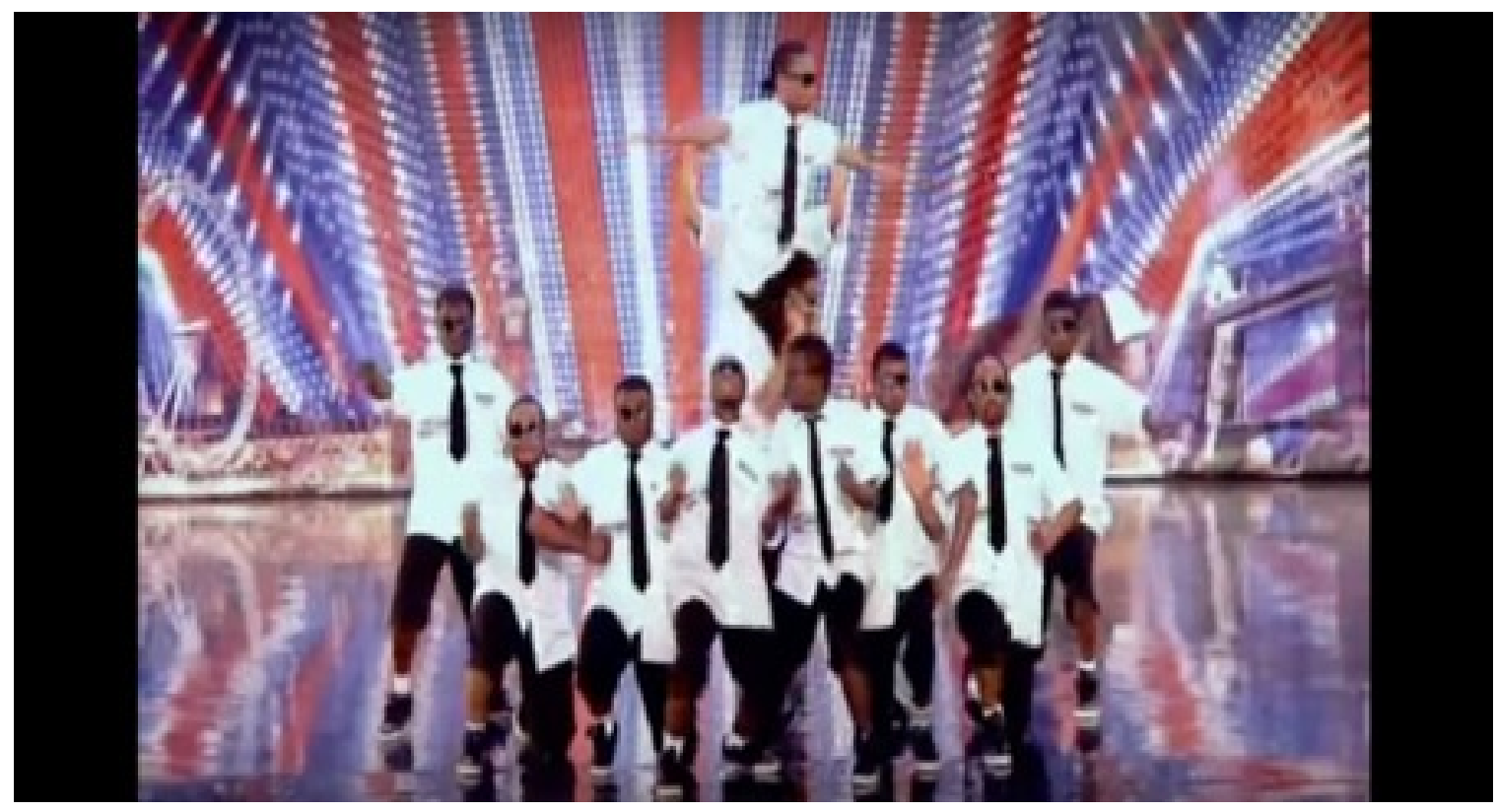

Figure 9 Abyss

In their final in GTD series three, Antics merge to form a racing car with one dancer upside down on their head with their legs splayed to create the chassis and two dancers supporting him to form the wheels. ${ }^{52}$ In terms of the transformation into digitally enhanced beings, $A$ byss's semi-final performance features the sequential splitting and morphing of the body into a twelve-piece robotic machine, achieved through the choreography and the slow camera zoom out from a darkened close-up shot. ${ }^{53}$

This morphing between styles, objects, and animals is further augmented through the competitions' own camerawork and edit. The mixture of live and pre-recorded material allows additional 'excessive' stylistic features in the editing process, including slow motion sequences and the rapid cutting of takes in montage sequences. Prior to Flawless's semi-final performance, the introductory VT segment features short bursts of the most explosive moments of their audition routine..$^{54}$ These include a brief shot of a symmetrical group formation, a dancer running over the backs of the other crew members and an aerial windmill stunt. For Diversity, the recap of their audition performance in the VT segment before their semi-final condenses the performance into twelve seconds of footage. ${ }^{55}$ Viewers witness sped up athletic stunts, explosive moments of unison, reactions of the judges through medium close-up shots, and freeze frames of the group hugging at their reaction to making it through to the semi-final. Edits also include the insertion of computer graphics, such as phone numbers and names of crews, as well as the frequent use of visible transitions in between frames, including dissolving or fading out the frame into the next image. 


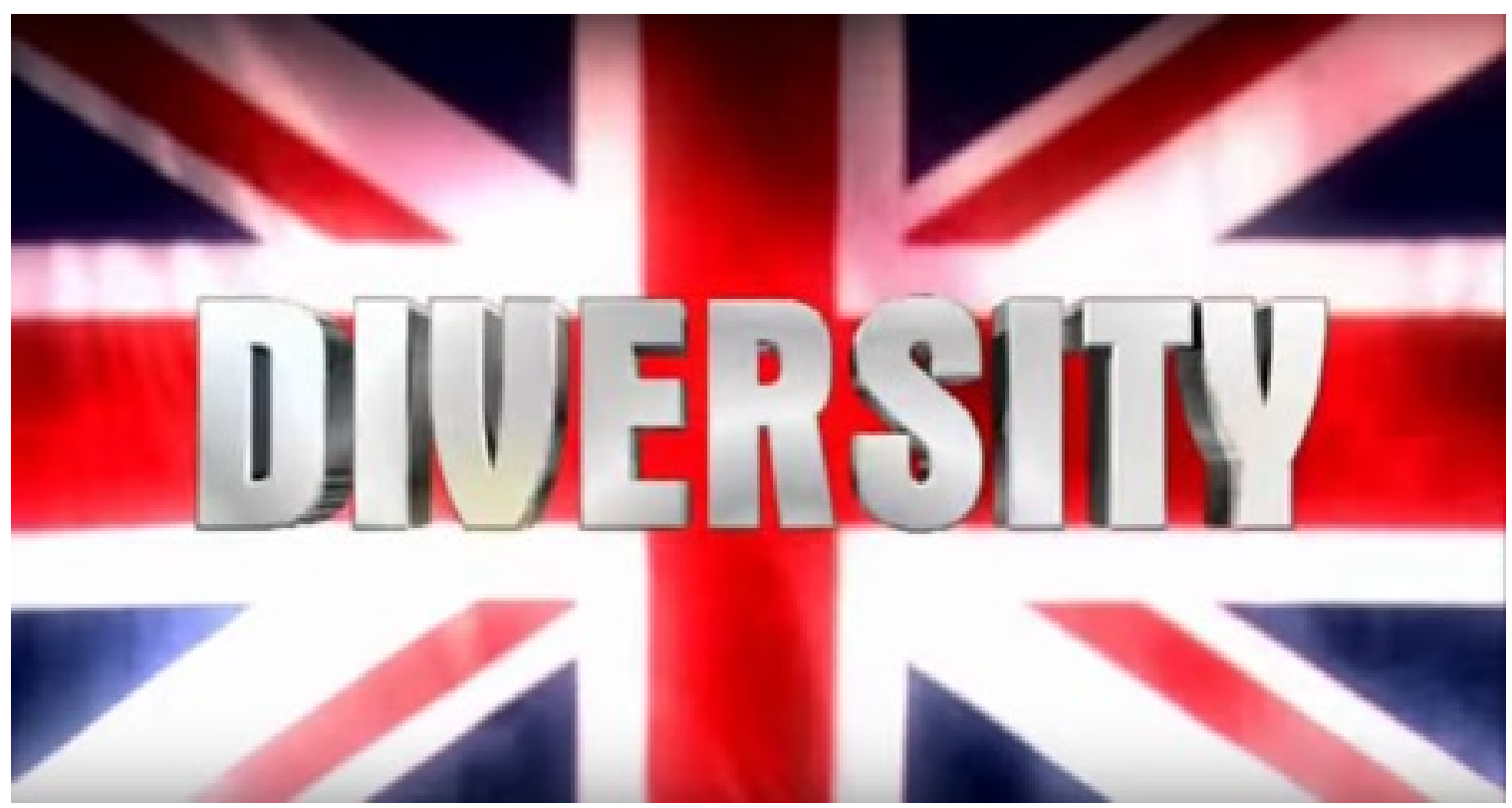

Figure 10 DiversityVT segment

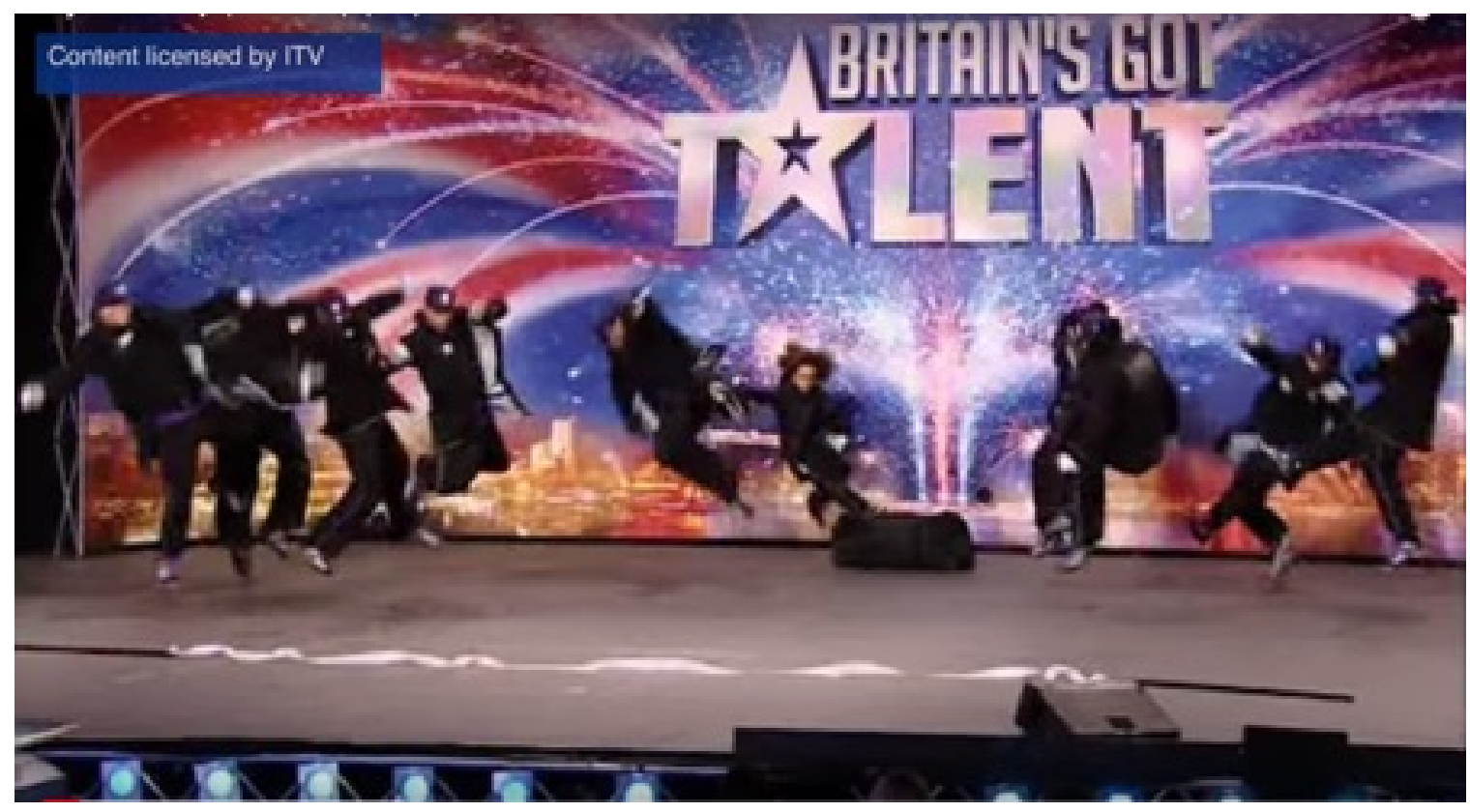

Figure 11 DiversityVT segment

In her work on digital special effects, Whissel focuses on the cinematic convention of the morph: the visual effect of a seamless transition from a source image into a target image. ${ }^{56}$ Inspired by the magic lantern shows of the nineteenth century, she describes this seamless metamorphosis as the promise of endless transformation, where the optical result is a "display of instantaneous transformation" that unfolds on screen. ${ }^{57}$ This transformation from one figure into another is particularly apparent in crews' 
transformations into cartoon characters. In Twist and Pulse's final performance on BGT, the duet use vigorous arm gestures as if they are in dialogue, while a squeaky voiceover states "Hey guys it's Twist and Pulse, the cartoon." ${ }^{\text {"58 }}$ The duet launch into a series of rapid angular arm isolations, body popping and waving to give the appearance of a fastpaced physical conversation between the two dancers, who stretch and bend their bodies at a rapid pace in an elasticated fashion. Executing rapid arm gestures that shoot out across a horizontal plane, Twist and Pulse create the illusion of blurred motion in a two-dimensional cartoon animation, where the complexity of the body is flattened to the properties of the television screen. ${ }^{59}$ As quickly as these characters are created, crews quickly morph into another section of the choreography.

In a cinematic context, Whissel maintains that morphing effects speak to ideas of freedom, and go further to mobilize "fantasies of transcendence involving any type of rigid categorization - zoological, behavioural, social, spatial and historical." ${ }^{160}$ While the spectacular morph effect witnessed in the choreography and the post production edit grabs the attention of the viewer, it also becomes emblematic of the wider themes of the reality television experience. In the context of the television talent show, ordinary people can achieve social mobility through the format of these programs. ${ }^{61}$ Personal accounts of their backgrounds in VT segments constructs contestants as ordinary, ready for them to make the transition to the 'better' life of celebrity. Through the choreographic and digital effect of transformation, viewers witness crews change before their eyes, morphing into an improved version of themselves through the neoliberal framework of the competition.

Alongside reflecting themes of personal transformation, the crews' metamorphosis into machines and digital beings, as well as their digital manipulation by the edit, puts into question fixed notions of identity. In her feminist study of the gendered cyborg, Balsamo states that "cyborg imagery can suggest a way out of the maze of dualisms in which we have explained our bodies and our tools to ourselves." ${ }^{162}$ The disruptive potential of the cyborg collapses the boundaries between social reality and science fiction and signals the reconsideration of the material body away from the contested binary identity markers of gender, race, creed, biology and class. By morphing into spectacular images of superhuman cyborgs and machinery, crews problematize the notion of the essentialized black entertainer and blur the boundaries between binary discourses that surround the material body.

These transformations also make a subtle nod towards discourses of Afrofuturism: "a way of imagining possible futures through a black cultural lens. ${ }^{163}$ Operating as both an artistic expression and a framework for critical theory, Afrofuturism, according to Ytasha Womack, "combines elements of science fiction, historical fiction, speculative fiction, fantasy, Afro-centricity, and magic realism with non-western beliefs." ${ }^{164}$ Afrofuturism breaks down racial, ethnic and social limitations in order to empower black individuals and to "create aspirational space that speaks to social ambitions enlivened by artmaking 
practice. ${ }^{165}$ The transformation of material bodies of crew members into science fiction inspired organisms in the choreography, as well as the digital intervention of the postproduction edit that manipulates crew performances, offers a differing representation of black hypermasculinity in the constraints of the television production. Similar to the Afrofuturist possibility explored through the cinematic world of Black Panther and its technologically advanced state of Wakanda, crew performances render new futures through the techno-corporeality of their choreography.$^{66}$ This transformation from the material to the mechanical, as an aesthetic experience, thus operates as emblematic of the reimagining of an Afrofuture, where black bodies might exist without the threat of physical and discursive death. Through the re-valuing of spectacle as an aesthetic experience, these cyborgian-inspired performances of black hypermasculinity thus begin to reveal spaces of creative possibility and potential.

\section{Conclusion}

While televised street dance crew performances may not always provide the vehicle for black transformations within the restrictive neoliberal framework of the talent show competition, the re-valuation of spectacle as an aesthetic experience can offer alternate readings regarding the representation of blackness on screen. Rather than dismissing these performances as commercial spectacles that recirculate limited notions of black hypermasculinity, these corporeal and televisual special effects instead highlight the thematic narratives of the reality television journey. Building upon Whissel's concept of the emblematic nature of the special effect in cinema, ${ }^{67}$ I suggest that the creation of spectacular and glossy images on screen enable the potentiality of more expansive gender and racialized representations. Through their physical labor, televised crew performances aspire to transform, both financially through their exposure in the television programs, and ontologically through their reimagining of fixed notions of hypervisibility. The playful creation of superheroes, cartoons, animals and cyborgs, manipulated by camera angles and editing, operates as both light entertainment and as a reimagining of black visual representation. By valuing screendance spectacles as a form of worldmaking for these dance crews, dancing black bodies can therefore inhabit alternative modes of visuality, and re-choreograph their histories and potential (Afro)futures within the current milieu of televisual spectacle.

\section{Biography}

Dr. Laura Robinson is Lecturer in Dance at the University of East London, and teaches on the BA (Hons) Dance: Urban Practice degree. Her PhD research focused on the 
construction of spectacle and excess in male Street dance crew performances on U.K. television talent show competitions. Publications include chapters in Bodies of Sound: Studies across Popular Music and Dance (2013) The Oxford Handbook of Dance and the Popular Screen (2014), as well as a chapter in the forthcoming publication, The Oxford Handbook of Dance and Competition (2019). Laura sits on the executive board of PoP MOVES, the international working group for popular dance and popular performance research, and the Society for Dance Research.

Email: laura.robinson@uel.ac.uk

\section{Notes}

${ }^{1}$ Rainer, "Some Retrospective Notes," 51. Yvonne Rainer's No Manifesto aimed to revolutionize dance and reduce it to its essential elements.

${ }^{2}$ Benthaus, "Hovering on Screen," 1.

${ }^{3}$ DeFrantz, "Hip-Hop Habitus," 238.

${ }^{4}$ Lavik, "The Battle for the Blockbuster," 176.

${ }^{5}$ Galt, Pretty, 2.

${ }^{6}$ Debord, Society of the Spectacle.

${ }^{7}$ ITV's Britain's Got Talent is the U.K. version of the Got Talent franchise. Sky1's Got To Dance is a dance talent competition open to all ages, size of groups and dance genres. As a result of these new opportunities for exposure and an increase in prize money, fifty-eight duet, trio and group all male Street dance performances featured at the audition, semi-final and final rounds between 2008-2013.

${ }^{8}$ DeFrantz and Gonzalez, Black Performance Theory, 1.

${ }^{9}$ Several scholars situate the trope of blackness in the power structures of institutions that appropriate and reaffirm fixed notions of racial identity. For more details, see: Fanon, "The Fact of Blackness," Mercer, Welcome to the Jungle; Hall, Representation, Gilroy, 'There Ain't No Black in the Union Jack, Gilroy, The Black Atlantic, Gilroy, Between Camps, Benston, Performing Blackness, Johnson, Appropriating Blackness, and Markovitz, Racial Spectacles.

${ }^{10}$ hooks, We real Cool, xii. 
${ }^{11}$ For more details on the stereotypical depiction of the Black male, see: Dent, Black Popular Culture, Elam and Jackson, Black Cultural Traffic, and Nakamura, Digitizing Race.

${ }^{12}$ Malik, Representing Black Britain.

${ }^{13}$ Ibid. 130.

${ }^{14}$ For more details on the construction of the masculinized self through breaking, see: Banes, "Physical Graffiti," Banes, "Breaking," Rose, Black Noise, Hazzard-Gordon, "Dance in Hip Hop Culture," DeFrantz, Dancing Many Drums, DeFrantz, "The Black Beat Made Visible," and DeFrantz, "Hip-hop in Hollywood."

${ }^{15}$ For more details on how the Hip-hop dancing body as commodity has come to represent consumable images of 'blackness', see: Scott, "Dance"; Osumare, The Africanist Aesthetic in Global Hip-hop, Huntingdon, Hip Hop Dance, and Arzumanova, "It's sort of 'members only.'"

${ }^{16}$ Fleetwood. Troubling vision.

${ }^{17}$ Grey. Black Masculinity and Visual Culture.

${ }^{18}$ Fleetwood. Troubling vision.

${ }^{19}$ Huntingdon, Hip Hop Dance, 116.

20 "Cerebro Audition- Got to Dance," YouTube.

${ }^{21}$ These phrases are more regularly used on Got To Dance, where judge feedback is solely focused on choreography.

22 Interviews feature on "Flawless Britains Got Talent 2009 Semi Final HD Dance Act," "A-Team Got to Dance Semi-Finals- Full Feature + Message," and "Got to Dance 4 Live Final: Ruff Diamond."

${ }^{23}$ Smith. As a result of mass movement to cities and the underdevelopment of urban centers, Valerie Smith states that "the idea of the urban has become virtually synonymous with notions of blackness" 2-3.

${ }^{24}$ Darley, Visual Digital Culture.

${ }^{25}$ Ibid. 6.

${ }^{26}$ Galt, Pretty.

${ }^{27}$ Ibid. 11. Arabesque camera movement refers to the composed fluid, curving lines of the shot, achieved through the cranes and tracking motions of the camera lens. 
${ }^{28}$ Whissel, Spectacular Digital Effects.

${ }^{29}$ Ibid. 13.

${ }^{30}$ Ibid. 4.

31 "Got to Dance 4 Live Final: Ruff Diamond."

32 "Got To Dance Series 3: Urban Jokers Semi Final."

33 "Got To Dance Series 3: Antics Audition."

${ }^{34}$ Whissel, Spectacular Digital Effects, 21-22.

${ }^{35}$ Ibid. 24.

36 "A3- Britain's Got Talent 2010- Semi-final 5."

37 "Got to Dance 4 Live Final: Ruff Diamond."

38 "Flawless-Britains Got Talent 2009."

39 "Got to Dance 4 Live Final: Ruff Diamond Final 3."

${ }^{40}$ Whissel, Spectacular Digital Effects.

${ }^{41}$ Ibid. 27.

${ }^{42}$ The League of Extraordinary Dancers (2010-2011) (known as the LXD) is a web based that follows the story of two rival gangs who have extraordinary powers in the form of hip-hop dance skills.

${ }^{43}$ Nama, SuperBlack, 4.

${ }^{44}$ Ibid. 2.

${ }^{45}$ Black Panther (2018).

46 "Got To Dance Series 3: Antics Audition."

47 "Got To Dance Series 3: Antics Final Performance."

48 "Got To Dance 4: Antics Performance."

49 "Got To Dance 4 Live Final: Antics."

50 "Back2Back | Audition | Got To Dance Series 2."

51 "Abyss Street Dance Group Britains Got Talent 2011HD."

52 "Got To Dance Series 3: Antics Final Performance." 
53 "Britains got talent- Abyss semi-finals."

54 "Flawless Britains Got Talent 2009 Semi Final HD Dance Act."

55 “Diversity (Winners) (HQ) Semi final BGT 2009."

${ }^{56}$ Whissel, Spectacular Digital Effects.

${ }^{57}$ Ibid. Famous examples of the morph effect include the transformation in Dr. Jekyll and Mr. Hyde.

58 "Twist and Pulse - Britain's Got Talent 2010 - The Final."

${ }^{59}$ For more information on animation techniques, see Osborn, Cartoon character animation with maya.

${ }^{60}$ Whissel, Spectacular Digital Effects, 17.

${ }^{61}$ Andrejevic, Reality TVand Biressi and Nunn, Reality TV: Realism and Revelation.

${ }^{62}$ Balsamo, Technologies of the Gendered Body, 57. Balsamo's ideas are based on Donna Haraway's seminal essay, "A manifesto for Cyborgs."

${ }^{63}$ Ingrid laFleur in Womack, Afrofuturism, 9.

64 Ibid.

${ }^{65}$ DeFrantz, "Afrofuturist Remains," 220.

${ }^{66}$ Staples, "The Afrofuturism Behind 'Black Panther.'"

${ }^{67}$ Whissel, Spectacular Digital Effects.

\section{References}

"A3- Britain's Got Talent 2010- Semi-final 5." Britain's Got Talent, 2010. (Last modified 01/08/2011). YouTube.

“Abyss Street Dance Group Britains Got Talent 2011HD." Megaroyalwedding2011, 2011. (Last modified 01/08/2011). YouTube.

"A-Team Got to Dance Semi-Finals- Full Feature + Message." TheATeam, 2012. (Last modified 11/09/2013). YouTube. 
Andrejevic, Mark. Reality TV: The Work of Being Watched. Ed. Lanham, Md: Rowman and Littlefield Publishers, 2004.

Arzumanova, Inna. 'It's Sort of "Members Only"': Transgression and Body Politics in Save the Last Dance. Ed. M. Blanco Borelli. The Oxford Handbook of Dance and the Popular Screen. Oxford: Oxford University Press, 2014. 166-181. https://doi.org/10.1093/oxfordhb/9780199897827.001.0001

"Back2Back | Audition | Got To Dance Series 2." Got To Dance, 2010. (Last modified 01/08/2011). YouTube.

Balsamo, Anna. Technologies of the Gendered Body: Reading Cyborg Women. 3rd edition. Durham: Duke Univ. Press, 1999.

Banes, Sally. "Physical graffiti: Breaking is hard to do." Village Voice, April 22-28, (1981): 31-33.

. Breaking. Eds. M. Forman and M. Neal. That's the Joint!: The Hip-hop Studies Reader. 1st edition. London and New York: Routledge, 1985, 2004. 14-20.

Benston, Kimberley. W. Performing Blackness: Enactments of African-American Modernism. London两nd New York: Routledge, 2000.

Benthaus, Elena. "Hovering on Screen: The Wow-affect and Fan Communities of Affective Spectatorship on So You Think You Can Dance." The International Journal of Screendance, 5, (2015): 11-28. https://doi.org/10.18061/ijsd.v5i0.4423

Biressi, Anita and Heather Nunn. Reality TV: Realism and Revelation. London: Wallflower Press, 2005.

Black Panther. Dir. Ryan Coogler. USA: Marvel Studios. 2018. Film.

"Britains got talent-Abyss semi-finals." OurLennox, 2011, (Last modified 11/09/2013). YouTube.

“Cerebro Audition-Got to Dance." Got To Dance, 2011, (Last modified 09/06/2012). YouTube.

Darley, Andrew. Visual Digital Culture: Surface Play and Spectacle in New Media Genres. London and New York: Routledge, 2000.

Debord, Guy. Society of the Spectacle. Trans. by K. Knabb. London: Rebel Press. 1967, 2004.

Dent, Gina. Ed. Black Popular Culture. Seattle: Bay Press, 1992.

DeFrantz, Thomas, F. Dancing Many Drums: Excavations in African American Dance. Madison, Wisconsin: University of Wisconsin Press, 2002. 
. "The Black Beat Made Visible: Body Power in Hip Hop Dance." Ed. A. Lepecki. Of the Presence of the Body: Essays on Dance and Performance Theory. Middletown, CT: Wesleyan University Press. 2004. 64-81.

"Hip-hop in Hollywood: Encounter, Community, Resistance." Ed. M. Blanco Borelli. The Oxford Handbook of Dance and the Popular Screen. Oxford: Oxford University Press, 2014. 113-131.

https://doi.org/10.1093/oxfordhb/9780199897827.001.0001

. “Hip-Hop Habitus V.2.0." Eds. Thomas F. DeFrantz and Anita Gonzalez. Black Performance Theory. Durham: Duke University Press Books, 2014.223-242. https://doi.org/10.1215/9780822377016

. "Afrofuturist Remains: A Speculative Rendering of Social Dance Futures v2.0." Eds. Thomas F. DeFrantz and Philipa Rothfield. Choreography and Corporeality: Relay in Motion. London: Palgrave Macmillan, 2016. 209-222.

DeFrantz, Thomas F. and Anita Gonzalez. Black Performance Theory. Durham: Duke University Press Books, 2014. https://doi.org/10.1215/9780822377016

"Diversity (Winners) (HQ) Semi final BGT 2009." Spiritman, 2009.[Last modified01/08/2011]. YouTube.

Dr. Jekyll and Mr. Hyde. Dir. Rouben Mamoulian. USA: Paramount Pictures. 1931. Film. Dr. Jekyll and Mr. Hyde. Dir. Victor Fleming. USA: MGM, 1941. Film.

Elam, Harry J. and Jackson, Kennel. Eds. Black Cultural Traffic: Crossroads in Global Performance and Popular Culture. Ann Arbor: University of Michigan Press, 2005. https://doi.org/10.3998/mpub.11883

Fanon, Frantz. "The Fact of Blackness." Eds. J. Evans and S. Hall. Visual Culture: The Reader. London, Thousand Oaks and New Delhi: Sage Press, 1952, 1999. 417-420.

"Flawless-Britains Got Talent 2009." BritainsSoTalented, 2009. (Last modified 01/08/2011). YouTube.

"Flawless Britains Got Talent 2009 Semi Final HD Dance Act." BorisKnez, 2009. (Last modified 01/08/2011). YouTube.

Fleetwood, Nicole R. Troubling Vision: Performance, Visuality, and Blackness. Chicago: The University of Chicago Press, 2011.

Galt, Rosalind. Pretty: Film and the Decorative Image. New York: Columbia University Press, 2011. 
Gilroy, Paul. 'There ain't no black in the union jack': The cultural politics of race and nation. London: Hutchinson, 1987.

_. The Black Atlantic: Modernity and double consciousness. London: Verso, 1993.

$\ldots$. Between camps $₫$ Nations, cultures and the allure of race. London: Allen Lane. 2000.

"Got to Dance Cerebro Semi Final." Got To Dance, 2011, (Last modified 09/06/2012). YouTube.

"Got To Dance Series 3: Antics Audition." Got To Dance, 2012, (Last modified 11/09/2013). YouTube.

"Got To Dance Series 3: Antics Final Performance." Got To Dance, 2012. (Last modified 11/09/2013). YouTube.

"Got To Dance Series 3: Antics Semi Final." Got To Dance, 2012. (Last modified 11/09/2013). YouTube.

"Got To Dance Series 3: Urban Jokers Semi Final." Got To Dance, 2012. (Last modified 11/09/2013). YouTube.

"Got To Dance 4: Antics Performance." Got To Dance, 2013. (Last modified 11/09/2013). YouTube.

"Got To Dance 4 Live Final: Antics." Got To Dance, 2013. (Last modified 11/09/2013). YouTube.

"Got to Dance 4 Live Final: Ruff Diamond." Got To Dance, 2013, (Last modified 11/09/2013). YouTube.

"Got to Dance 4 Live Final: Ruff Diamond Final 3." Got To Dance, 2013. (Last modified 11/09/2013). YouTube.

Grey, Herman. “Black Masculinity and Visual Culture.” Callaloo, 18, 2, (1995): 401-405.

Hall, Stuart. Representation: Cultural Representations and Signifying Practices. London, Thousand Oaks and New Delhi: Sage Press, 1997.

Haraway, Donna. "A Manifesto for Cyborgs: Science, Technology, and Socialist Feminism in the 1980s." Eds. G. Kirkup, J.Janes, K.Woodward and F. Hovenden. The Gendered Cyborg: A Reader. London泊nd New York: Routledge in association with the Open University, 1985, 2000. 50-57.

Hazzard-Gordon, Katrina. “Dance in Hip Hop Culture." Ed. W.E. Perkins. Droppin' Science: Critical Essays on Rap Music and Hip Hop Culture. Philadelphia: Temple University Press. 1996, 220-237. 
hooks, bell. We Real Cool: Black Men and Masculinity. New York: Routledge, 2004.

Huntingdon, Carla Stalling. Hip Hop Dance: Meanings and Messages. North Carolina: McFarland and Co., 2007.

. Black Social Dance in Television Advertising. North Carolina: McFarland and Co., 2011.

Johnson, E. Patrick. Appropriating Blackness: Performance and the Politics of Authenticity. Durham: Duke University Press, 2003.

https://doi.org/10.1215/9780822385103

Lavik, Erlend. "The Battle for the Blockbuster: Discourses of Spectacle and Excess." New Review of Film and Television Studies, 6, 2008: 169-187.

https://doi.org/10.1080/17400300802098305

The League of Extraordinary Dancers. Dir. Jon. M Chu. Hulu, 2010-2011. Web series.

Malik, Sarita. Representing Black Britain: A History of Black and Asian Images on British Television. London and Thousand Oaks: SAGE Publications, 2002.

Markovitz, Jonathan. Racial Spectacles: Explorations in Media, Race, and Justice. New York: Routledge, 2011.

Mercer, Kobena. Welcome to the Jungle: New Positions in Black Cultural Studies. London and New York: Routledge, 1994.

Nakamura, Lisa. Digitizing Race: Visual Cultures of the Internet. Minneapolis: University of Minnesota Press, 2008.

Nama, Adilifu. Super Black: American Pop Culture and Black Superheroes. 1st edition. Austin: University of Texas Press, 2011.

Osumare, Halifu. The Africanist Aesthetic in Global Hip-Hop: Power Moves. 1st edition. New York: Palgrave Macmillan, 2007. https://doi.org/10.1007/978-1-137-05964-2

Rainer, Yvonne. "Some Retrospective Notes on a Dance for 10 People and 12 Mattresses Called Parts of Some Sextets, Performed at the Wadsworth Athenaeum, Hartford, Connecticut, and Judson Memorial Church, New York, in March 1965," Tulane Drama Review, 10 (Winter 1965): 51. https://doi.org/10.2307/1125242

Rose, Tricia. Black Noise: Rap Music and Black Culture in Contemporary America. Hanover NH: University Press of New England, 1994.

Scott, Anna Beatrice. Dance. Ed. R. Maxwell. Culture Works: the Political Economy of Culture. Minneapolis: University of Minnesota Press. 2001. 107-130. 
Smith, Valerie. "Introduction." Ed. V. Smith. Representing Blackness: Issues in Film and Television. New Brunswick, New Jersey: Rutgers University Press, 1997. 1-12.

Staples, Brent. "The Afrofuturism Behind 'Black Panther."' New York Times Sunday Review, 24 February 2018. Online.

"Twist and Pulse - Britain's Got Talent 2010 - The Final." Britain's Got Talent, 2010, (Last modified 01/08/2011). YouTube.

Whissel, Kristen. Spectacular Digital Effects: CGI and Contemporary Cinema. Durham and London: Duke University Press, 2014. https://doi.org/10.1215/9780822377146 Womack, Ytasha. Afrofuturism: The World of Black Sci-fi and Fantasy Culture. 1st edition. Chicago: Chicago Review Press, 2013. 